\title{
Effectiveness of Mindfulness Interventions for Mental Health in Schools: a Comprehensive Meta-analysis
}

\begin{abstract}
Mindfulness interventions have increasingly been incorporated in elementary and high school classrooms to support students' mental health and well-being; however, there is little research examining the specific factors contributing to the effectiveness of the interventions. The purpose of this meta-analysis was to examine the specific effects of and moderators contributing to school-based mindfulness interventions for mental health in youth. A systematic review of studies published in PsycINFO, ERIC, Social Work Abstracts, Social Services Abstracts, and CINAHL was conducted. A total of 24 studies $(n=3977)$ were included in the meta-analysis. Overall, mindfulness interventions were found to be helpful, with small to moderate significant effects pre-post intervention compared to control groups (Hedges' $g=0.24, p<.001$ ); however, interventions that were delivered during late adolescence (15-18) and that consisted of combinations of various mindfulness activities had the largest effects on mental health and wellbeing outcomes. Furthermore, the effects on specific mindfulness and mental health outcomes differed according to whether the intervention was delivered by an outside facilitator compared to trained educators/teachers. These results suggest that individual differences and program characteristics can impact receptivity and effectiveness of mindfulness training. These findings represent a significant contribution as they can be used to inform future designs and applications of mindfulness interventions in the school setting.
\end{abstract}

A focus for schools in recent years has been to address students' mental health challenges (Carsley and Heath 2015; Koller and Bertel 2006; McMartin et al. 2014), as one in five children and adolescents have reported significant mental health difficulties (e.g., anxiety, depression) 
during their school years (CMHA 2014; NIMH 2015). Mindfulness programs have become an increasingly popular form of intervention in schools to support students' mental health and overall well-being (e.g., Felver et al. 2016; Tan 2016; Zoogman et al. 2014). Mindfulness includes the act of nonjudgmentally and purposefully paying attention to and being aware of present moment experiences (Kabat-Zinn 2003). Numerous mindfulness-based programs intended for adults have since been adapted into school for children and adolescents to support their mental health in the classroom (e.g., Burke 2010; Harnett and Dawe 2012; Kallapiran et al. 2015).

Within the past decade, many studies have evaluated the effectiveness of mindfulnessbased programs for children and adolescents in the school setting and have highlighted the potential of these programs for supporting youth across a variety of outcomes such as mental health issues (see Felver et al. 2016 for review); however, there is limited research examining whether individual differences (e.g., developmental period, gender) as well as program characteristics (e.g., type of mindfulness intervention, training of the facilitator) have the potential to impact effectiveness of and students' response to mindfulness training. To support educators in providing targeted and effective mindfulness training programs that meet the mental health needs of their students, an examination of these potential contributing factors is required.

Youth with mental health problems have been shown to experience challenges related to academics and school functioning such as lower academic performance, greater behavioral and attendance problems, and higher levels of dropout relative to youth who are not experiencing mental health difficulties (e.g., Koller and Bertel 2006; McLeod et al. 2012; Owens et al. 2012). Given that students spend the majority of their time in schools and that many groups of students can be reached directly in their classrooms (Weare and Nind 2011; Zenner et al. 2014), there has 
been a recent and considerable increase in the inclusion of mindfulness interventions and prevention programs to support students' mental health in the classroom.

"Mindfulness" originated from ancient Buddhist and Eastern perspectives in which it was regarded as a comprehensive awareness and alertness on the present (Bodhi 2011; Dalai Lama \& Berzin 1997). Mindfulness became increasingly popular in the West throughout the 1990s, in which it has been regarded as a specific way of paying attention and being aware of the moment (Miller et al. 1995) and as an individual state, combining an awareness of the moment with both attention and openness to experiences (Langer 1992). In Western psychology, mindfulness is described as (1) a theoretical construct, (2) a type of practice (e.g., mindfulness meditation), and (3) a psychological state (e.g., being mindful; Germer 2005). Mindfulness can be considered as both a process and as an outcome in which individuals practice mindfulness while also maintaining a goal of being mindful. Specifically, in addition to a state of mindfulness, this construct has also been shown to incorporate a combination of meditative and practical elements. For instance, Kabat-Zinn (2003) has advocated that mindfulness includes a practical component, in which the ability to experience present moment awareness and nonjudgmental focused attention of one's experiences can occur through mindfulness-type practices.

To consider a practice as "mindful," it should include structured activities for participants to be able to focus their attention and control their physical and mental activity (Greenberg and Harris 2012). Structured programs that are 5-10 weeks in length, such as mindfulness-based stress reduction (MBSR), are the most common approaches to integrating mindfulness practices into a cohesive program as they focus on regular and structured mindfulness exercises that are practiced and eventually improved over time (Burke 2010; Kabat-Zinn 2003). Mindfulnessbased programs have been shown to be effective for mental health outcomes in both clinical and 
nonclinical populations for individuals of all ages (e.g., Khoury et al. 2013, 2015; Zoogman et al. 2014). Many of the existing school-based mindfulness programs for mental health (e.g., Learning to BREATHE, Mindfulness in Schools Program) have been adapted from MBSR to meet children's and adolescents' developmental needs and shorter attention spans (Britton et al. 2014; Broderick and Metz 2009; Zoogman et al. 2014). These programs include a number of mindfulness-based activities such as breath awareness, psycho-education components, bodyscans, sitting meditations, and mindful movement, among others (Kabat-Zinn 1990; Zenner et al. 2014). Mindfulness can be practiced differently according to the duration and type of intervention, as well as the sample of participants (Kallapiran et al. 2015). Most recently, researchers have begun to investigate the impact of various combinations of brief (e.g., 1-4 weeks) mindfulness-based activities (e.g., mindful eating, body awareness, breathing, walking meditation, mindfulness-based coloring), as well as mindfulness-based yoga interventions. These activities have been shown to be effective on improving mental health and well-being outcomes in school settings (e.g., Atkinson and Wade 2015; Carsley et al. 2015; Huppert and Johnson 2010; Parker et al. 2014).

To evaluate this wide range of mindfulness interventions for mental health outcomes with youth, several comprehensive reviews and meta-analyses have been conducted. For instance, Zoogman et al. (2014) conducted a meta-analysis on mindfulness interventions for youth and their findings revealed larger effect sizes on psychological symptoms relative to other outcome variables (e.g., physiological, cognitive). Despite these promising findings, this meta-analysis did not focus solely on mindfulness interventions conducted in educational settings as there were a number of studies drawn from clinical settings, and studies were only included up to 2011 . There has been an increase in the popularity of mindfulness interventions and research within the past 
several years (Zenner et al. 2014), particularly in the school setting; therefore, a more recent analysis of these mindfulness interventions in schools should be considered to accurately represent the current effects of these interventions. Furthermore, the focus on the effectiveness of the actual intervention in previous research fails to consider the influence of specific developmental periods and other potentially critical considerations for school delivery of these programs such as the individual delivering the program (e.g., classroom educator versus outside facilitator).

In a recent meta-analysis, Kallapiran et al. (2015) found that mindfulness-based interventions were associated with decreased anxiety, depression, and stress in clinical and nonclinical youth samples (i.e., children and adolescents); however, similar to Zoogman et al.'s study (2014) this analysis was not limited to in-school applications of mindfulness as clinical populations were included as well. Educational settings are in a unique position to support students' mental health as school services (1) are extremely accessible, (2) can help decrease the stigma associated with mental illness, and (3) can be cost-effective relative to clinical or hospital support (Carsley and Heath 2015; Mazzer and Rickwood 2015; Stephan et al. 2007; Weare and Nind 2011). Zenner et al. (2014) conducted a meta-analysis on mindfulness interventions in schools for psychological outcomes (e.g., stress, anxiety, affect) and revealed promising findings such as improved stress resilience in the school setting; however, the heterogeneity in the studies limited the generalization of the findings and the authors recommended that more information on the interventions should be provided in future research (e.g., teacher experience, duration) to allow for a more comprehensive meta-analysis. There has been an increase in mindfulness intervention studies that include specific information detailing the study design. These studies continue to represent a broad range of mindfulness activities for varying duration, and they have 
been shown to be effective. To determine if the inclusion of these activities in schools is beneficial, it would be important to assess the impact of factors that are critical to school delivery, as well as program characteristics that are essential for resource and curriculum considerations.

The Developmental Contemplative Science Framework (DCS) considers the importance of assessing the impact of development on response to mindfulness intervention. DCS is concerned with understanding the mind-body system for use in a curriculum of mental training in education (i.e., mindfulness) with the objective of enhancing human development within and across developmental periods (e.g., Frank et al. 2013; Roeser 2013; Roeser and Pinela 2014; Roeser and Zelazo 2012). DCS is part of the social-emotional learning (SEL) field, which focuses on the mechanisms by which individuals (1) use knowledge, attitudes, and skills for understanding and managing emotions; (2) set and accomplish positive goals and demonstrate empathy for others; (3) create and maintain positive relationships; and (4) make responsible choices (CASEL 2015). According to this framework, there are three core premises in which mindfulness operates and impacts response to training. First, it has been suggested that the brain adapts in response to experience, intentional training, and education (e.g., mindfulness activities); specifically, physiological changes can result from neuroplasticity. Second, engaging in regular mindfulness activities will eventually lead to increases in daily mindfulness; specifically, mindfulness training can lead to changes in day-to-day cognitive and emotional processes. Third, there are certain developmental periods, such as adolescence (ages 13-18), in which specific brain regions and networks are more likely to be modified, and these periods can predispose an individual to be open to training. As such, the DCS framework suggests that response to mindfulness training and potential effectiveness of mindfulness training will differ 
between developmental periods (Roeser and Pinela 2014; Roeser and Zelazo 2012). To determine if these periods (e.g., middle childhood, early-late adolescence) have an effect on response to training, an examination of this factor in school-based mindfulness interventions is required.

In addition to the possible impact of development periods on effectiveness of mindfulness interventions, there is limited knowledge on whether gender can also impact effectiveness of school-based mindfulness training. Many of the earlier mindfulness studies have not reported on gender differences due to having predominantly male or female samples (e.g., Broderick and Metz 2009; Huppert and Johnson 2010); however, there have been some recent studies examining the impact of gender on response to mindfulness training and these studies have indicated that females may respond more positively to a mindfulness-based activity (Carsley et al. 2015; Parker et al. 2014). Although there is limited research regarding the impact of gender on mindfulness, the preliminary studies assessing mindfulness and gender have revealed early evidence that gender may impact students' response to mindfulness training. Given that there has been an increase in the number of mindfulness studies in schools within the past years, and many of these recent studies have reported more balanced gender samples than previous studies (e.g., Bakosh et al. 2016; Bernay et al. 2016), an examination of possible gender differences would inform the research and school community on appropriate and targeted mindfulness interventions for males and females.

As previously mentioned, a number of studies conducted on mindfulness training in schools have included different types of interventions. In addition to the existing mindfulness programs that have been pre-packaged/designed and manualized, researchers have investigated mindfulness-based yoga interventions on various mental health and well-being outcomes 
(Bergen-Cico et al. 2015; Mendelson et al. 2010), whereas other studies have combined several mindfulness-based activities to form an intervention (e.g., mindfulness eating, breath awareness, guided meditation; Atkinson and Wade 2015; Bernay et al. 2016). In a previous meta-analysis, it was reported that there have been many exploratory studies on a number of mindfulness interventions that have not been manualized (Zenner et al. 2014); however, researchers have not assessed and compared the effects that these interventions have on mental health outcomes. Thus, an examination of the type of intervention being implemented is important to consider.

Studies have shown that classroom teachers can be trained to deliver mindfulness interventions, whereas some interventions are delivered by outside facilitators (e.g., researchers, graduate students). A number of stress management studies have found that school-based programs are particularly beneficial when teachers are involved in the training and delivery of the program, as they are in a position to ensure consistency and connectedness with the students over time (Frydenberg et al. 2004; Garcia et al. 2010; Hampel et al. 2008). To support educators in providing the most effective mindfulness programs for their students, it would be helpful to assess if the identity of the facilitator (e.g., teacher, outside deliverer) affects the response to training.

To accurately measure effects of mindfulness on mental health and well-being outcomes in educational settings in different developmental periods, a comprehensive meta-analysis will be conducted. The first objective of this meta-analysis is to determine the strength of the effects of school-based mindfulness interventions on mental health and well-being outcomes. Subsequently, the second objective is to examine and compare the strength of the effects of the moderators for these interventions based on (1) developmental periods, (2) gender groups, (3) type of mindfulness intervention, and (4) the identity of the facilitator. The current meta-analysis 
will provide important information on the potential role of individual differences and intervention characteristics across developmental periods in the effectiveness of mindfulness school-based interventions.

\section{Method}

\section{Eligibility Criteria}

Studies considered in the analyses were mindfulness interventions conducted in elementary and high schools with students' ages ranging from 6 to 18 years old. Studies were included if they (1) were published in a peer-reviewed journal; (2) included quantitative data; (3) focused on a sample of students from nonspecialized populations (e.g., not at-risk, high-risk, clinical); (4) were conducted at school; and (5) included a measure of mental health or wellbeing. Studies were selected for analyses if mindfulness was the primary focus of the intervention. Specifically, interventions that included established mindfulness-based programs (e.g., MBSR), or new/modified interventions with mindfulness as a central component were selected. Finally, if the studies did not report sufficient data to compute effect sizes, authors were contacted; if the authors were unable to provide the necessary data, those studies were excluded from analyses (see Fig. 1 for a detailed flowchart with specific exclusions).

\section{Information Sources}

Studies were identified through a systematic search of published articles on mindfulness interventions with youth in the school setting from the first available date until March 2017. The electronic databases included in the search were PsycINFO, ERIC, Social Work Abstracts, Social Services Abstracts, and CINAHL. 


\section{Search}

Keywords used in the search were "mindfulness" combined with "school," "children," “adolescent*," "class," and "classroom*." Reference lists of articles were also inspected, as well as monthly reports on new mindfulness research (American Mindfulness Research Association 2010-2016).

\section{Study Selection}

The authors conducted standardized assessments to determine study eligibility. Of the studies selected, two authors were unable to provide the information required; as such, these two studies were excluded from analyses. Twenty-four studies were included for review (see Table 1 for an overview of the included studies).

\section{Data Collection Process}

Data were collected during November 2016 and revised in March 2017 to ensure consistency between the searches.

\section{Data Items}

The following information was extracted from each study: (1) characteristics of the total sample (sample size, mean age [or age range if mean was not provided], percentage of females), (2) characteristics of the intervention and control groups (number of participants in each group, type of control condition), (3) information on the intervention (type of intervention, facilitator), and (4) characteristics of the study (type of outcome measures, follow-up time in weeks).

\section{Summary Measures}


Standardized differences in means were computed for the analyses. All analyses were performed using the Comprehensive Meta-Analysis software, Version 3.3.070 (CMA; Borenstein et al. 2014).

\section{Synthesis of Results}

Means and standard deviations $(S D)$ were used to compute effect sizes. When means and SDs were not available, other statistics (e.g., $t$ and $F$ ) were used to compute effect sizes. A conservative estimate of .7 was used for the within-group analyses when pre-post intervention measures correlations were not available (Rosenthal 1993). The effect size computed in all studies was Hedges' $g$, with the associated $p$ value, and its $95 \%$ confidence interval. Hedges' $g$ was used as it represents a less biased estimate of effect size for small samples (Hedges and Olkin 1985). The studies included in the analyses did not have identical designs and samples; therefore, a random effects model was used to calculate mean effect sizes for a group of studies.

\section{Risk of Bias in Individual Studies}

Data pertaining to all mental health and well-being outcomes (i.e., anxiety, depression, stress, test anxiety) were included to minimize the influence of data selection. Data pertaining to mindfulness outcomes were included as well. When data from follow-up was available, they were also included.

A quality score comprised of items based on Jadad's criteria (Jadad et al. 1996) and items pertaining to mindfulness was computed. These items consisted of whether (1) the mindfulness intervention was an established program; (2) measures were assessed at follow-up; (3) mindfulness was measured; (4) the facilitator was an outsider; and (5) the facilitator had mindfulness training. When studies were controlled, items included whether (1) participants 
were randomly assigned to a mindfulness intervention or control group; (2) participants in either group spent the same amount of time participating in the intervention; and (3) evaluators/experimenters and/or participants were blind to the purpose of the study. When items were binary (i.e., true or false), a value of 1 was assigned to a true item and a value of 0 was assigned to a false item. A value of 0 was assigned to pre-post studies; a value of 1 was assigned to studies with either a waitlist or no-treatment control group; a value of 2 was assigned to studies with a treatment-as-usual control group; and a value of 3 was assigned to studies with an active control group. A value of 0 was assigned to nonblinded studies; a value of 1 was assigned to single-blind studies; and a value of 2 was assigned to double-blind studies.

Inter-rater agreement was calculated by comparing the ratings of the first author with the rating of a trained graduate research assistant. Each evaluator received (1) a training session on the rating procedure, (2) specific written instructions for the rating procedure, and (3) a set of articles to review.

\section{Risk of Bias Across Studies}

A funnel plot was constructed and a fail-safe $\mathrm{N}$ was computed to assess publication bias, which is the possibility that studies with significant results are more likely to be published than studies with nonsignificant findings.

\section{Additional Analyses}

The objectives of the analysis were to assess specific effects of individual differences and intervention characteristics for school-based mindfulness interventions. Moderators included in the analyses were (1) developmental periods (organized into four groups based on previous research and theories on developmental periods and stages (Eccles 2007; McDevitt et al. 2013): 
middle childhood [ages 6-10], early adolescence [11-14], late adolescence [15-18], and other [when the age groupings represented a combination of periods]); (2) gender (organized into three groups: males-only, females-only, or mixed [both males and females]); (3) type of mindfulness intervention (organized into four groups: mindfulness-based yoga, pre-designed or established mindfulness program, combinations of various mindfulness activities, and other); and (4) identity of the program facilitator (organized into two groups: teacher/educator trained to deliver the program and outside facilitator). Interventions were considered to be mindfulness programs when the intervention consisted of a pre-packaged or manualized mindfulness program, unlike various mindfulness activities, which included a combination of mindfulness-based activities without a manual or pre-packaged format.

To assess the effect of specific moderators reported as continuous variables, metaregression analyses were conducted for the within-group effects. In this meta-regression, two additional moderators were included: (1) gender (the percentage of female participants in the studies) and (2) changes in mindfulness (as indicated by the effect sizes within the studies).

\section{Results}

\section{Study Selection}

Searches among the various databases generated 1072 publications. Figure 1 represents the study selection process.

\section{Study Characteristics}

Table 1 reports the study characteristics and effect sizes (Hedges' $g$ ). There were a total of 3977 participants, with 2179 in the mindfulness intervention groups and 1798 in the control 
groups. Twenty-two studies were conducted since 2010, and two studies were conducted between 2000 and 2009. All studies included school-based interventions.

\section{Risk of Bias Within Studies}

Nine studies were conducted during middle childhood, seven studies were conducted during early adolescence, seven studies were conducted during late adolescence, and one study did not fit either category as it covered a wide range of developmental periods. Twenty studies included both males and females, and four studies consisted of only females. Thirteen studies assessed a pre-designed or existing mindfulness program, six studies used a combination of various mindfulness activities, four studies indicated mindfulness-based yoga as their primary focus, and one study was classified as other as it consisted of an arts-based mindfulness activity. Nine studies were delivered by a trained teacher and 15 studies were delivered by an outside facilitator. Of the 15 studies delivered by an outside facilitator, 12 studies included an experienced mindfulness practitioner or teacher as the facilitator and the remaining three studies

included researchers and graduate students as facilitators. Active control conditions consisted of topics related to academics, health education, and social responsibility, among other unrelated activities. Ten studies included at least one mindfulness measure, and four studies used a mindfulness measure at follow-up. The quality score ranged from a minimum of 0 (i.e., lowest quality) to a maximum of 10 (highest quality), with a mean of $6.08(S D=2.21)$ and a median of 6. Inter-rater agreement was high (kappa $=.93)$.

\section{Results of Individual Studies}

Table 1 presents the post-intervention and last follow-up effects (Hedges' $g$ ) for the within-group (pre-post, pre-follow-up) and between-group (intervention vs. control) samples. 
Similar to post-intervention effects, follow-up effects were derived from a comparison of followup to pre-intervention to determine if the mindfulness intervention was associated with long-term change. A lack of follow-up effect would indicate a return to baseline/pre-intervention.

\section{Synthesis of Results}

Effect sizes (Hedges' $g$ ) for the within-group and between-group analyses pre-post intervention and pre-follow-up intervention are presented in Table 1. Between-group effect sizes refer to effects pre-post intervention compared to a control group; within-group effect sizes refer to effects pre-post intervention when not compared to a control group. Significant effect sizes (Hedges' $g$ ) and associated 95\% confidence intervals, $\mathrm{p}$ values, and heterogeneity for target populations (i.e., I 2 and Q) and outcome measures reported in the analyses below are provided in Table 2. Follow-up periods varied across the studies from 12 to 32 weeks with a weighted mean of 17.74 weeks.

\section{Overall Findings}

Results revealed significant small effect sizes on mental health and well-being outcomes for within-group studies at post-test $(n=20$; Hedges' $g=0.23,95 \% \mathrm{CI}[.12, .34], p<.001)$ and at follow-up ( $n=8$; Hedges' $g=0.17,95 \% \mathrm{CI}[.04, .30], p=.013)$ and for between-group studies at post-test ( $n=21$; Hedges' $g=0.24,95 \%$ CI $[.14, .34], p<.001)$. These findings were not significant for between-group studies at follow-up ( $n=6$; Hedge's $g=.17, p=.079$ ).

\section{Developmental Period}

In the within-group analyses, studies conducted in late adolescence ( $n=7$; Hedges' $g=$ $0.28,95 \% \mathrm{CI}[.17, .39], p<.001)$ revealed higher pre-post effects than middle childhood $(n=6$; Hedges' $g=0.20,95 \% \mathrm{CI}[.03, .37], p=.023)$ on mental health and well-being outcomes; 
however, pre-post effects of the studies conducted during early adolescence were not significant ( $n=6$; Hedges' $g=0.11, p=.213$ ). Similar results were found in the between-group analyses, with studies conducted in late adolescence ( $n=7$; Hedges' $g=0.35,95 \%$ CI $[.18, .52], p<.001)$ demonstrating higher effects than middle childhood ( $n=7$; Hedges' $g=0.22,95 \%$ CI $[0.04$, $0.40], p=.017)$ and nonsignificant effects during early adolescence $(n=6$; Hedges' $g=.30, p=$ .064). Furthermore, studies conducted in late adolescence showed significant but small effects at follow-up in both the within-group ( $n=4$; Hedges' $g=0.33,95 \%$ CI $[.25, .42], p<.001)$ and between-group analyses $(n=3$; Hedges' $g=0.22,95 \%$ CI $[.56, .39], p=.009)$.

\section{Gender}

The studies included in the analyses were either mixed or composed of females-only. Results from both within-group and between-group analyses revealed similar significant effects on mental health and well-being outcomes for both gender group compositions at post-test. The mixed gender and females-only studies revealed small effects at post-test (mixed: $n=17$;

Hedges' $g=0.23,95 \%$ CI $[.10, .37], p<.001$; females: $n=3$; Hedges' $g=0.24,95 \%$ CI [.15, $.34], p<.001)$. These findings were comparable in the between-group analyses as well (mixed: $n$ $=17$; Hedges' $\mathrm{g}=0.22,95 \%$ CI [.10, .34], $p<.001$; females: $n=4$; Hedges' $g=0.27,95 \%$ CI $[.10, .45], p=.003)$

\section{Type of Intervention}

In the within-group analyses, studies that were either yoga-based or composed of various mindfulness activities had a significant effect on mental health and well-being outcomes at posttest (yoga: $n=2$; Hedges' $g=0.29,95 \%$ CI $[.14, .45], p<.001$; various: $n=6$; Hedges' $g=0.39$, 95\% CI $[.14, .64], p=.003$ ) and at follow-up (yoga: $n=1$; Hedges' $g=0.22,95 \%$ CI $[.04, .40]$, 
$p=.017$; various: $\mathrm{n}=2$; Hedges' $g=0.34,95 \%$ CI $[.24, .43], p<.001)$; these effects were higher than in the between-group analyses at post-test (yoga: $n=3$; Hedges' $g=0.24,95 \%$ CI [.05, 0.44 ], $p=.015$; various: $n=5$; Hedges' $g=0.29,95 \% \mathrm{CI}[.10,0.48], p=.003$ ), but lower than the between-group analyses at follow-up (yoga: $n=1$; Hedges' $g=0.30,95 \%$ CI [.10, .48], $p=$ .003 ; various: $n=2$; Hedges' $g=0.23,95 \%$ CI $[.03, .43], p=.027)$. Existing mindfulness programs did not have a significant effect at post-test ( $n=11$; Hedges' $g=0.13, p=.07$ ) or at follow-up ( $n=5$; Hedges' $g=0.06, p=.406$ ) in the within-group analyses, but these programs had a small effect at post-test in between-group analyses ( $n=12$; Hedges' $g=0.22,95 \%$ CI [.06, $.38], p=.006)$.

\section{Facilitator}

In within-group analyses, studies facilitated by a trained teacher had a smaller effect on mental health and well-being outcomes at post-test ( $n=8$; Hedges' $g=0.19,95 \%$ CI [.06, .32], $p$ $=.005)$ than those delivered by an outside facilitator $(n=12$; Hedges' $g=0.28,95 \%$ CI [ .09 , $.46], p=.003)$; however, at follow-up, a significant effect on mental health and well-being outcomes was found only when interventions were delivered by teachers $(n=2$; Hedges' $g=$ $0.15,95 \% \mathrm{CI}[.06, .24], p<.001)$ and not by an outside facilitator $(n=6 ; p=.084)$. In betweengroup analyses, interventions facilitated by a trained teacher had a greater effect at post-test $(n=$ 8 ; Hedges' $g=0.28,95 \%$ CI $[.12, .45], p<.001)$, than those delivered by an outside facilitator ( $n$ $=13$; Hedges' $g=0.20,95 \%$ CI $[.07, .33], p=.003)$; however, the greatest effect was found at follow-up when interventions were delivered by a trained teacher $(n=2$; Hedges' $g=0.32,95 \%$ CI $[.16, .48], p<.001)$. 
In between-group analyses, the effect of the facilitator was assessed on (1) mental health outcomes only (e.g., anxiety, depression, stress) and (2) mindfulness outcomes only. For mental health outcomes, effects were only significant when the intervention was delivered by a trained teacher at post-test $(n=5$; Hedges' $g=0.36,95 \%$ CI $[.24, .48], p<.001)$ unlike the outside facilitator $(n=9 ; p=.832)$. For mindfulness outcomes, effects were only significant at post-test when the intervention was delivered by an outside facilitator $(n=7$; Hedges' $g=0.38,95 \%$ CI $[.10, .67], p=.009)$ as opposed to a trained teacher $(n=2 ; p=.259)$. These results suggest that the type of facilitator can have an impact on the outcomes of the studies.

\section{Additional Analyses}

The within-group effect size of mental health and well-being outcomes (e.g., stress, anxiety, depression) was weakly positively moderated by the percentage of female participants, $(n=17, \beta=0.02, S E=0.01, p<.01)$ and strongly positively moderated by changes in mindfulness outcomes $(n=4, \beta=0.78, S E=0.39, p<.05$; see Fig. 2). Furthermore, the effect size of mental health and well-being outcomes was weakly positively moderated by the study quality score for both the within-group $(n=20, \beta=0.04, S E=0.01, p<.01)$ and between-group $(n=21, \beta=0.03, S E=0.01, p<.01)$ studies.

\section{Publication Bias}

An effect size for mental health and well-being outcomes for all within-group analyses revealed a $z$ value of $10.13, p<.001$. These findings indicate that to nullify the results, 515 studies with a null effect would be required, with a $p$ value exceeding .05. According to Duval and Tweedie's Trim and Fill method, to make the funnel plot symmetric, only one study would need to fall on the left side of the mean (see Fig. 3). The adjusted mean effect size for the random 
effects model was Hedges' $g=0.18,(95 \%$ CI $[.05, .30])$. Similar results were obtained for between-group analyses, which revealed a $z$ value of $6.10, p<.001$, and a fail-safe $\mathrm{N}$ of 183 . Employing Duval and Tweedie's (2000) Trim and Fill method, to make the funnel plot symmetric, only one study would need to fall on the left side of the mean. The adjusted mean effect size for the random effects model was Hedges' $g=0.22$, (95\% CI $[.11, .33])$. The adjusted means do not significantly differ from the original Hedges' $\mathrm{g}$ for the mental health and wellbeing outcomes (Hedges' $g=0.17$ ) and mindfulness outcomes (Hedges' $g=0.15$ ); as such, these results suggest robust and unbiased effect size estimates and a low probability of publication bias.

\section{Discussion}

The purpose of this meta-analysis was (1) to assess the strength of the effects of schoolbased mindfulness interventions on mental health and well-being and (2) to evaluate and compare the effects of these interventions based on (a) developmental periods, (b) gender, (c) type of mindfulness intervention, and (d) the identity of the facilitator of the intervention. This meta-analysis included 24 studies evaluating mindfulness-based interventions in schools with a total of 3977 participants.

The overall effect sizes for mental health and well-being outcomes found for the withingroup and between-group analyses were small, but similar to the small-moderate effect sizes found in previous meta-analyses on mindfulness intervention programs with youth and in schools (Zenner et al. 2014; Zoogman et al. 2014). These effect sizes are smaller than those found in meta-analyses with clinical samples (Khoury et al. 2013) and healthy adults (Khoury et al. 2015). Although mindfulness-based interventions have been shown to be effective for mental health and well-being outcomes, many of the mindfulness-based interventions for youth have been adapted 
from the programs designed for adults; as such, it is likely that further modifications are required to ensure that the interventions are targeted for youth in the school setting.

Interventions delivered during late adolescence (15-18) were found to have the greatest effect on mental health and well-being at post-test and at follow-up for both the within-group and between-group analyses, with interventions delivered in middle childhood (6-10) demonstrating a significant effect at post-test only. According to the DCS theory, response to mindfulness training can differ between developmental periods (Roeser and Pinela 2014; Roeser and Zelazo 2012) as there are specific stages in which particular brain regions and networks are more likely to be modified. These findings suggest that late adolescence may represent a developmental period in which students can respond to and experience the benefits of mindfulness training both immediately once the training is completed and several months following. Adolescence is considered to be a "window of opportunity" (Roeser and Pinela 2014); specifically, the plasticity in adolescents' brains and the associated social and cognitive systems essential to development during adolescence are malleable as they co-construct adolescents' identity. Consistent with the DCS theory, specific brain regions and networks are more likely to be modified in adolescence, and these periods can predispose an individual to be open and responsive to mindfulness training. Adolescents' development is shaped by what is influencing them, and mindfulness training may be particularly effective during this transitional period. In addition, given that late adolescence (15-18) is close to adulthood, research on further adaptations to the existing mindfulness interventions for students in earlier stages might be required (Burke 2010) in order for these younger students to experience mindfulness and mental health benefits (Zoogman et al. 2014). 
The findings revealed small effects for studies with (1) females-only and (2) mixed gender (male and female), and (3) when the percentage of females was included as a moderator. Meta-regression analyses showed a significant effect such that the greater the percentage of females included in the study, the greater the effects are on mental health and well-being, suggesting that females may respond better to mindfulness interventions; however, this link was very small, and the finding does not consider the possibility that males in these studies may have shown high effect sizes despite the fact that there were fewer of them in the sample. Although there were studies with only female participants, there were no studies with solely male participants. These results suggest that a clear examination of specific gender differences was not possible. To accurately assess the role of gender in mindfulness-based interventions, future studies should either (1) report if gender differences were found or (2) report the descriptive statistics for the different gender groups in addition to the intervention and control groups. These additions would allow future meta-analyses to compare the differences and potential impacts of gender on mindfulness-based interventions.

The types of interventions demonstrating significant effects at both post-test and at follow-up consisted of combinations of various mindfulness activities and yoga-based mindfulness activities. Existing or pre-designed mindfulness programs only revealed a small effect at post-test in the between-group analysis. A possible explanation is that the existing mindfulness programs rely too heavily on the facilitator's ability and familiarity with mindfulness, and if the facilitator was not trained in mindfulness, he or she might struggle with adhering to the program (Crane et al. 2012). Although the teachers in the study were trained to deliver the mindfulness intervention, the authors do not always indicate whether the facilitator of the program has an established mindfulness practice. As such, future studies should examine the 
impact of the mindfulness practice of the facilitator on the effectiveness of the intervention. Additionally, it is possible that existing mindfulness interventions are not well suited to the specific needs and reality of a classroom. Attention to specific developmental (e.g., cognitive ability, attention spans) and school needs is required when adapting an existing MBSR-type program (Burke 2010). When students are provided with a collection of various activities, the facilitator may be more likely to adapt activities according to the students' response, as the program is not pre-designed.

Overall, when trained teachers delivered the program, there were significant effects at follow-up, unlike when the program was delivered by an outside facilitator. This finding is important to our understanding of mindfulness program delivery; given that teachers remain with their students in the classroom upon completion of the study, it is likely that teachers are more involved and familiar with the program they delivered and are thus more likely to continue incorporating elements of the intervention with their students (Britton et al. 2014), which can lead to consistently positive findings at follow-up.

When mental health outcomes and mindfulness outcomes were examined separately in the between-group analyses, the effects on mental health outcomes post-test were only significant when interventions were delivered by a trained teacher; however, the effects on mindfulness post-test were only significant when interventions were delivered by an outside facilitator. These results suggest that the facilitator plays an important role in determining the material that is being delivered to the students. For instance, in two recent meta-analyses, the authors revealed that increases on mindfulness accounted for 12 to $16 \%$ of improvements on psychological outcomes in mindfulness-based interventions (Khoury et al. 2013, 2015); however, the findings of the current meta-analysis suggest that the individual delivering the 
program may be more knowledgeable on a particular topic which is influencing the message that is being communicated. In fact, in a large meta-analysis, the mindfulness training of the facilitator(s) was found to significantly moderate the clinical outcomes $(n=154 ; \beta=.13, S E=$ $.04, p<.0005)$ but not their clinical training $(p=.07$, ns; Khoury et al. 2013).

Addressing the mental health needs of students has become an increasing focus in schools (Carsley and Heath 2015; Koller and Bertel 2006; McMartin et al. 2014); therefore, it is possible that teachers are more aware and informed on this topic and are already addressing this need within their classrooms. These interventions provide them with opportunities to continue supporting their students' mental health, and students may be more likely to respond to this ongoing support from their teachers as they have had more time to establish trust in their relationship (Garcia et al. 2010). In addition, the teachers delivering the program likely interpreted and incorporated the taught skills with a greater focus on the mental health (e.g., using the breath to manage anxiety) rather than focusing on the goal of enhancing mindfulness (e.g., using the breath to maintain present moment awareness without judgment). As such, the difference among the facilitators could be attributed to the way in which the skill was taught and repeated over time with the students, which may have benefitted mental health outcomes, rather than enhancing mindfulness. An explanation for the students' positive mindfulness response to the outside facilitator could be due to the facilitator's previous experience with mindfulness (Zenner et al. 2014). Given that mindfulness can be a complex construct that is difficult to define, it is possible that students are better able to understand and explain their experience when an outside facilitator is delivering the intervention, as an outside facilitator may have greater knowledge of and personal experience with mindfulness compared to a teacher who was trained on mindfulness only for the purpose of a given study (Zenner et al. 2014). 
The meta-regression analysis also revealed that the changes in mindfulness effects from pre- to post-intervention significantly moderated changes in mental health and well-being outcomes prepost intervention, such that participants with greater increases in mindfulness also reported greater changes/benefits on mental health and well-being outcomes. These results are consistent with previous meta-analyses (e.g., Khoury et al. 2013, 2015), suggesting that increase of selfreport on mindfulness is a strong predictor of the psychological effects of mindfulness interventions. Although the studies included in this meta-regression were limited, these findings show that when participants are experiencing the mindfulness benefits, they are also experiencing the targeted mental health benefits of the intervention.

The results showed that mental health and well-being outcomes were very weakly moderated by the quality score of the study. Previous research has shown that quality score does not typically moderate the outcomes (Khoury et al. 2015; Hofmann et al. 2010); however, when the quality score has been shown to be a significant moderator, the coefficient is extremely small (e.g., Khoury et al. 2013), similar to the present study's finding.

Despite these findings, this research is not without limitations. First, although all of the studies included a mindfulness school-based intervention on mental health and well-being outcomes, it is important to acknowledge that there was variability in the studies (e.g., sample size, length of intervention). A number of factors were included in the analyses to account for these differences, such as intervention design and identity of the facilitator; however, these results should be interpreted with caution. In the future, researchers should consider examining other moderators that potentially influence program effectiveness, such as the length of the program, the impact of at-home practice, as well as participants' response by age in addition to 
developmental periods to create even more targeted mindfulness intervention programs. Nevertheless, the results demonstrated that mindfulness activities have a significant, albeit small, effect on mental health and well-being in youth. Second, a proper examination of gender differences was not possible given the limited information provided in the studies. Future studies should consistently report gender findings and descriptive statistics for each gender group within each of the intervention and control groups to allow for this type of analysis. Third, although the between-group studies included a combination of different comparison groups (e.g., active controls, treatment as usual, and waitlist controls), when examining these comparison groups separately, findings were either not significant, or they consisted of only one study per group. As such, findings were compared with overall control groups rather than separate groupings. Future studies would benefit from including more active controls as the comparison group to allow future meta-analyses to compare the effects of the intervention with another similar activity. Fourth, studies were only examined if they were published in English; it would be interesting for future analyses of mindfulness interventions to include studies published in other languages to allow greater generalizability.

Despite these limitations, these findings represent a significant contribution to the theory and practice of school-based mindfulness interventions in youth as they provide preliminary evidence that effectiveness of the interventions differ according to (1) the age of students receiving the intervention, (2) the type of intervention that is being delivered, and (3) the individual facilitating the intervention. Furthermore, this meta-analysis is a significant contribution to the field as it provides suggestions for future applications of mindfulness in schools. The mental health of youth, who spend the majority of their day in school, should always be acknowledged in the education system (Zenner et al. 2014). Given that mindfulness 
interventions have become increasingly popular in schools as a way of supporting students' mental health and overall well-being (e.g., Felver et al. 2016; Tan 2016; Zoogman et al. 2014), it is important for schools to ensure that factors critical to school delivery (e.g., developmental period, type of intervention, and identity of facilitator) are considered when implementing the programs in such a way that students experience optimal benefits of mindfulness interventions. Furthermore, future studies that consider specific adaptations of mindfulness interventions should take into consideration the needs of students in the classroom across different developmental periods. 


\section{References}

American Mindfulness Research Association. (2010-2016). American Mindfulness Research Association: mindfulness research monthly, 1-7.

Atkinson, M. J., \& Wade, T. D. (2015). Mindfulness-based prevention for eating disorders: a school-based cluster randomized controlled study. International Journal of Eating Disorders, 48(7), 1024-1037.

Bakosh, L. S., Snow, R. M., Tobias, J. M., Houlihan, J. L., \& Barboas-Leiker, C. B. (2016). Maximizing mindful learning: mindful awareness intervention improves elementary school students' quarterly grades. Mindfulness, 7, 59-67. $\underline{\text { https://doi }}$ org.proxy3.library.mcgill.ca/10.1007/s12671-015-0387-6.

Bennet, K., \& Dorjee, D. (2016). The impact of a mindfulness-based stress reduction course (MBSR) on well-being and academic attainment of sixth-form students. Mindfulness, 7, 105-114. https://doi-org.proxy3.library.mcgill.ca/10.1007/s12671-015-0430-7.

Bergen-Cico, D., Razza, R., \& Timmins, A. (2015). Fostering self-regulation through curriculum infusion of mindful yoga: a pilot study of efficacy and feasibility. Journal of Child and Family Studies, 24, 3448-3461. https://doi-org.proxy3.library.mcgill.ca/10.1007/s10826015-0146-2.

Bernay, R., Graham, E., Devcich, D. A., Rix, G., \& Rubie-Davies, C. M. (2016). Pause, breathe, smile: a mixed-methods study of student well-being following participation in an eightweek locally developed mindfulness program in three New Zealand schools. Advances in 
School Mental Health Promotion, 9(2), 90-106. https://doi-

org.proxy3.library.mcgill.ca/10.1080/1754530X.2016.1154474.

Bodhi, B. (2011). What does mindfulness really mean? A canonical perspective. Contemporary Buddhism, 12(1), 19-39. https://doi-org.proxy3.library.mcgill.ca/10.1080/ 14639947.2011.564813.

Borenstein, M., Hedges, L., Higgins, J., \& Rothstein, H. (2014). Comprehensive meta-analysis (version 3). Englewoord: Biostat.

Britton, W. B., Lepp, N. E., Niles, H. F., Rocha, T., Fisher, N. E., \& Gold, J. S. (2014). A randomized controlled pilot trial of classroom-based mindfulness meditation compared to an active control condition in sixth-grade children. Journal of School Psychology, 52, 263-278. https://doi-org.proxy3.library.mcgill.ca/10.1016/j.jsp.2014.03.002.

Broderick, P. C., \& Metz, S. (2009). Learning to BREATHE: a pilot trial of a mindfulness curriculum for adolescents. Advances in School Mental Health Promotion, 2(1), 35-46. https://doi-org.proxy3.library.mcgill.ca/10.1080/1754730X.2009.9715696.

Burke, C. A. (2010). Mindfulness-based approaches with children and adolescents: a preliminary review of current research in an emergent field. Journal of Child and Family Studies, 19(2), 133-144. https://doi-org.proxy3.library.mcgill.ca/10.1007/s10926-009-9282-x.

Carsley, D., \& Heath, N. L. (2015). How can educational leaders promote mental health in 
schools? In D. Griffiths \& J. P. Portelli (Eds.), Key questions for educational leaders (pp. 241-250). Burlington: Word \& Deed Publishing Incorporated \& Edphil Books.

Carsley, D., Heath, N. L., \& Fajnerova, S. (2015). Effectiveness of a classroom mindfulness colouring activity for test anxiety in children. Journal of Applied School Psychology, 31(3), 239-255. https://doiorg.proxy3.library.mcgill.ca/10.1080/15377903.2015.1056925.

CASEL (2015). Collaborative for academic, social, and emotional learning. Retrieved from http://www.casel.org/social-and-emotional-learning/.

CMHA (Canadian Mental Health Association) (2014). Mental illness in Canada. Retrieved from http://alberta.cmha.ca/mental_health/statistics/\#.VO9zckJNla8.

Crane, R. S., Kuyken, W., Williams, J. M. G., Hastings, R. P., Cooper, L., \& Fennell, M. J. V. (2012). Competence in teaching mindfulness-based courses: concepts, development and assessment. Mindfulness, 3, 76-84. https://doiorg.proxy3.library.mcgill.ca/10.1007/s12671-011-0073-2.

Crescentini, C., Capurso, V., Furlan, S., \& Fabbro, F. (2016). Mindfulness-oriented meditation for primary school children: effects on attention and psychological well-being. Frontiers in Psychology, 7(805), 1-12. https://doiorg.proxy3.library.mcgill.ca/10.3389/fpsyg.2016.00805.

Dalai Lama, \& Berzin, A. (1997). The Gelug/Kagyu tradition of Mahamudra. New York: Snow Lion. 
Duval, S., \& Tweedie, R. (2000). Trim and fill: a simple funnel-plot-based method of testing and adjusting for publication bias in meta-analysis. Biometrics, 56(2), 455-463.

Eccles, J. S. (2007). The development of children ages 6 to 14. CYC-Online: Online Journal of the International Child and Youth Care Network, 106.

Feagans Gould, L., Dariotis, J. K., Mendelson, T., \& Greenberg, M. T. (2012). A school-based mindfulness intervention for urban youth: Exploring moderators of intervention effects. Journal of Community Psychology, 40(8), 968-982. https://doiorg.proxy3.library.mcgill.ca/10.1002/jcop.21505.

Felver, J. C., Celis-de Hoyos, C. E., Tezanos, K., \& Singh, N. H. (2016). A systematic review of mindfulness-based interventions for youth in school settings. Mindfulness, 7, 34-45. https://doi-org.proxy3.library.mcgill.ca/10.1007/s12671-015-0389-4.

Frank, J. L., Jennings, P. A., \& Greenberg, M. T. (2013). Mindfulness-based interventions in school settings: an introduction to the special issue. Research in Human Development, 10(3), 205-210.

Frydenberg, E., Lewis, R., Bugalski, K., Cotta, A., McCarthy, C., Lucombe-Smith, N., \& Poole, C. (2004). Prevention is better than cure: coping skills training for adolescents at school. Educational Psychology in Practice: Theory, Research and Practice in Educational Psychology, 20(2), 117-134. https://doiorg.proxy3.library.mcgill.ca/10.1080/02667360410001691053.

Garcia, C., Kemmick Pintor, J., \& Lindgren, S. (2010). Feasibility and acceptability of a school- 
based coping intervention for Latina adolescents. The Journal of School Nursing, 26(1), 42-52. https://doi-org.proxy3.library.mcgill.ca/10.1177/1059840509351021.

Germer, C. K. (2005). Mindfulness: what is it? What does it matter? In C. K. Germer, R. D. Siegel, \& P. R. Fulton (Eds.), Mindfulness and psychotherapy (pp. 3-27). New York: The Guilford Press.

Gouda, S., Luong, M. T., Schmidt, S., \& Bauer, J. (2016). Students and teachers benefit from mindfulness-based stress reduction in a school-embedded pilot study. Frontiers in Psychology, 7(590), 1-18. https://doiorg.proxy3.library.mcgill.ca/10.3389/fpsyg.2016.00590.

Greenberg, M. T., \& Harris, A. R. (2012). Nurturing mindfulness in children and youth: current state of research. Child Development Perspectives, 6(2), 161-166. https://doiorg.proxy3.library.mcgill.ca/10.1111/j.1750-8606.2011.00215.x.

Hampel, P., Meier, M., \& Kummel, U. (2008). School-based stress management training for adolescents: longitudinal results from an experimental study. Journal of Youth and Adolescence, 37, 1009-1024. https://doi-org.proxy3.library.mcgill.ca/10.1007/s10964007-9204-4.

Harnett, P. H., \& Dawe, S. (2012). Review: the contribution of mindfulness-based therapies for children and families and proposed conceptual integration. Child and Adolescent Mental Health, 17, 195-208.

Hedges, L., \& Olkin, I. (1985). Statistical methods for meta-analysis. Orlando: Academic Press. 
Hofmann, S. G., Sawyer, A. T., Witt, A. A., \& Oh, D. (2010). The effect of mindfulness-based therapy on anxiety and depression: a meta-analytic review. Journal of Consulting and Clinical Psychology, 78(2), 169-183. https://doiorg.proxy3.library.mcgill.ca/10.1037/a0018555.

Huppert, F. A., \& Johnson, D. M. (2010). A controlled trial of mindfulness in schools: the importance of practice for an impact on well-being. The Journal of Positive Psychology, 5(4), 264-274. https://doi-org.proxy3.library.mcgill.ca/10.1080/1743976100394148.

Jadad, A. R., Moore, R. A., Carroll, D., Jenkinson, C., Reynolds, D. J., Gavaghan, D. J., et al. (1996). Assessing the quality of reports of randomized clinical trials: Is blinding necessary? Controlled Clinical Trials, 17(1), 1-12. https://doiorg.proxy3.library.mcgill.ca/10.1016/01972456(95) 00134-4.

Johnson, C., Burke, C., Brinkman, S., \& Wade, T. (2016). Effectiveness of a school-based mindfulness program for transdiagnostic prevention in young adolescents. Behaviour Research and Therapy, 81,1-11. https://doiorg.proxy3.library.mcgill.ca/10.1016/j.brat.2016.03.002.

Joyce, A., Etty-Leal, J., Zazryn, T., \& Hamilton, A. (2010). Exploring a mindfulness meditation program on the mental health of upper primary children: a pilot study. Advances in School Mental Health Promotion, 3(2), 17-25. https://doiorg.proxy3.library.mcgill.ca/10.1080/1754730X.2010.9715677.

Kabat-Zinn, J. (1990). Full catastrophe living: using the wisdom of your body and mind to face 
stress, pain, and illness. New York: Bantom Dell.

Kabat-Zinn, J. (2003). Mindfulness-based interventions in context: past, present, and future.

Clinical Psychology: Science and Practice, 10(2), 144-156. https://doiorg.proxy3.library.mcgill.ca/10.1093/clipsy/bpg016.

Kallapiran, K., Koo, S., Kirubakaran, R., \& Hancock, K. (2015). Review: effectiveness of mindfulness in improving mental health symptoms of children and adolescents: a metaanalysis. Child and Adolescent Mental Health, 20(4), 182-194. https://doiorg.proxy3.library.mcgill.ca/10.1111/camh.12113.

Khoury, B., Lecomte, T., Fortin, G., Masse, M., Therien, P., Bouchard, V., ... Hofmann, S. G. (2013). Mindfulness-based therapy: a comprehensive meta-analysis. Clinical Psychology Review, 33, 763-771. doi: https://doiorg.proxy3.library.mcgill.ca/10.1016/j.cpr.2013.05.005.

Khoury, B., Sharma, M., Rush, S. E., \& Fournier, C. (2015). Mindfulness-based stress reduction for healthy individuals: a meta-analysis. Journal of Psychosomatic Research, 78, 519_528. https://doi-org.proxy3.library.mcgill.ca/10.1016/j.jpsychores.2015.03.009.

Koller, J. R., \& Bertel, J. M. (2006). Responding to today's mental health needs of children, families and schools: revisiting the preservice training and preparation of school-based personnel. Education and Treatment of Children, 29(2), 197-217.

Kukyen, W., Weare, K., Ukoumunne, O. C., Vicary, R., Motton, N., Burnett, R., ... Huppert, F. 
(2013). Effectiveness of the mindfulness in schools programme: non-randomised controlled feasibility study. The British Journal of Psychiatry, 203, 126-131. doi: https://doi-org.proxy3.library.mcgill.ca/10.1192/bjp.bp.113.126649.

Langer, E. J. (1992). Matters of mind: Mindfulness/mindlessness in perspective. Consciousness and Cognition, 1, 289-305.

Lau, N.-S., \& Hue, M.-T. (2011). Preliminary outcomes of a mindfulness-based programme for Hong Kong adolescents in schools: well-being, stress and depressive symptoms. International Journal of Children's Spirituality, 16(4), 315-330. https://doiorg.proxy3.library.mcgill.ca/10.1080/1364436X.2011.639747.

Mazzer, K. R., \& Rickwood, D. J. (2015). Teachers' role breadth and perceived efficacy in supporting student mental health. Advances in School Mental Health Promotion, 8(1), 29-41. https://doi-org.proxy3.library.mcgill.ca/10.1080/1754730X.2014.978119.

McDevitt, T. M., Omrod, J. E., Cupit, G., Chandler, M., \& Aloa, V. (2013). Child development and education. Frenchs Forest: Pearson Australia.

McLeod, J. D., Uemura, R., \& Rohrman, S. (2012). Adolescent mental health, behavior problems, and academic achievement. Journal of Health and Social Behavior, 53(4), 482497. https://doi-org.proxy3.library.mcgill.ca/10.1177/0022146512462888.

McMartin, S. E., Kingsbury, M., Dykxhoorn, J., \& Colman, I. (2014). Time trends in symptoms of mental illness in children and adolescents in Canada. Canadian Medical Association Journal, 186(18), E672. https://doi-org.proxy3.library.mcgill.ca/10.1503/cmaj.140064. 
Mendelson, T., Greenberg, M. T., Dariotis, J. K., Feagans Gould, L., Rhodas, B. L., \& Lead, P. J. (2010). Feasibility and preliminary outcomes of a school-based mindfulness intervention for urban youth. Journal of Abnormal Child Psychology, 38(7), 985-994.

Metz, S. M., Frank, J. L., Reibel, D., Cantrell, T., Sanders, R., \& Broderick, P. C. (2013). The effectiveness of the Learning to BREATHE program on adolescent emotion regulation. Research in Human Development, 10(3), 252-272. https://doiorg.proxy3.library.mcgill.ca/10.1080/15427609.2013.818488.

Miller, J. J., Fletcher, K., \& Kabat-Zinn, J. (1995). Three-year follow up and clinical implications of a mindfulness meditation-based stress reduction intervention in the treatment of anxiety disorders. General Hospital Psychiatry, 17, 192-200.

Napoli, M., Krech, P. R., \& Holley, L. C. (2005). Mindfulness training for elementary school students. Journal of Applied School Psychology, 21(1), 99-125.

NIMH (National Institute of Mental Health) (2015). Prevalence of any disorder among children. Retrieved from http://www.nimh.nih.gov.proxy3.library.mcgill.ca/health/statistics/prevalence/anydisorder-among-children.shtml.

Owens, M., Stevenson, J., Hadwin, J. A., \& Norgate, R. (2012). Anxiety and depression in academic performance: an exploration of the mediating factors of worry and working memory. School Psychology International, 33(4), 433-449.

Parker, A. E., Kupersmidt, J. B., Mathis, E. T., Scull, T. M., \& Sims, C. (2014). The impact of 
mindfulness education on elementary school students: evaluation of the Master Mind program. Advances in School Mental Health Promotion, 7(3), 184-204. https://doiorg.proxy3.library.mcgill.ca/10.1080/1754730X.2014.916497.

Raes, F., Griffith, J. W., Van der Gucht, K., \& Williams, J. M. G. (2014). School-based prevention and reduction of depression in adolescents: a cluster-randomized controlled trial of a mindfulness group program. Mindfulness, 5, 477-486. https://doiorg.proxy3.library.mcgill.ca/10.1007/s12671-013-0202-1.

Roeser, R. W. (2013). Mindfulness and human development: a commentary on the special issue. Research in Human Development, 10(3), 273-283.

Roeser, R. W., \& Pinela, C. (2014). Mindfulness and compassion training in adolescence: a developmental contemplative science perspective. New Directions for Youth Development, 142, 9-30.

Roeser, R. W., \& Zelazo, P. D. (2012). Contemplative science, education and child development: introduction to the special section. Child Development Perspectives, 6(2), 143-145.

Rosenthal, R. (1993). Meta-analytic procedures for social research. Newbury Park: Sage.

Schonert-Reichl, K. A., \& Lawlor, M. A. (2010). The effects of a mindfulness-based education program on pre- and early adolescents' well-being and social and emotional competence. Mindfulness, 1, 137-151. https://doi-org.proxy3.library.mcgill.ca/10.1007/s12671-0100011-8.

Schonert-Reichl, K. A., Oberle, E., Lawlor, M. S., Abbott, D., Thomson, K., Oberlander, T., \& 
Diamond, A. (2015). Enhancing cognitive and social-emotional development through a simple-to-administer mindfulness-based school program for elementary school children: a randomized controlled trial. Developmental Psychology, 51(1), 52-66.

Sibinga, E. M. S., Webb, L., Ghazarian, S. R., \& Ellen, J. M. (2016). School-based mindfulness instruction: an RCT. Pediatrics, 137(1), 1-8. https://doiorg.proxy3.library.mcgill.ca/10.1542/peds.2015-2532.

Stephan, S. H., Weist, M., Kataoka, S., Adelsheim, S., \& Mills, C. (2007). Transformation of children's mental health services: the role of school mental health. Psychiatric Services, 58(10), 1330-1338.

Tan, L. B. G. (2016). A critical review of adolescent mindfulness-based programmes. Clinical Child Psychology and Psychiatry, 21(2), 193-207. https://doiorg.proxy3.library.mcgill.ca/10.1177/1359104515577486.

Terjestam, Y., Bengtsson, H., \& Jansson, A. (2016). Cultivating awareness at school. Effects on effortful control, peer relations and well-being at school in grades 5, 7, and 8. School Psychology International, 37(5), 456-469. https://doiorg.proxy3.library.mcgill.ca/10.1177/0143034316658321.

Viafora, D. P., Mathiesen, S. G., \& Unsworth, S. J. (2015). Teaching mindfulness to middle school students and homeless youth in school classrooms. Journal of Child and Family Studies, 24, 1179-1191. https://doi-org.proxy3.library.mcgill.ca/10.1007/s10826-0149926-3. 
Weare, K., \& Nind, M. (2011). Mental health promotion and problem prevention in schools:

what does the evidence say? Health Promotion International, 26(51), 29-69. https://doiorg.proxy3.library.mcgill.ca/10.1093/heapro/dar075.

White, L. S. (2012). Reducing stress in school-age girls through mindful yoga. Journal of Pediatric Health Care, 26(1), 45-56. https://doiorg.proxy3.library.mcgill.ca/10.1016/j.pedhc.2011.01.002.

Zenner, C., Herrnleben-Kurz, S., \& Walach, Z. (2014). Mindfulness-based interventions in schools - a systematic review and meta-analysis. Frontiers in Psychology, 5, 1-20. https://doi-org.proxy3.library.mcgill.ca/10.3389/fpsyg.2014.00603.

Zoogman, S., Goldberg, S. B., Hoyt, W. T., \& Miller, L. (2014). Mindfulness interventions with youth: a meta-analysis. Mindfulness. https://doiorg.proxy3.library.mcgill.ca/10.1007/s12671-013-0260-4. 


\section{Tables and Figures}

Figure 1. PRSIMA flow diagram of study selection process

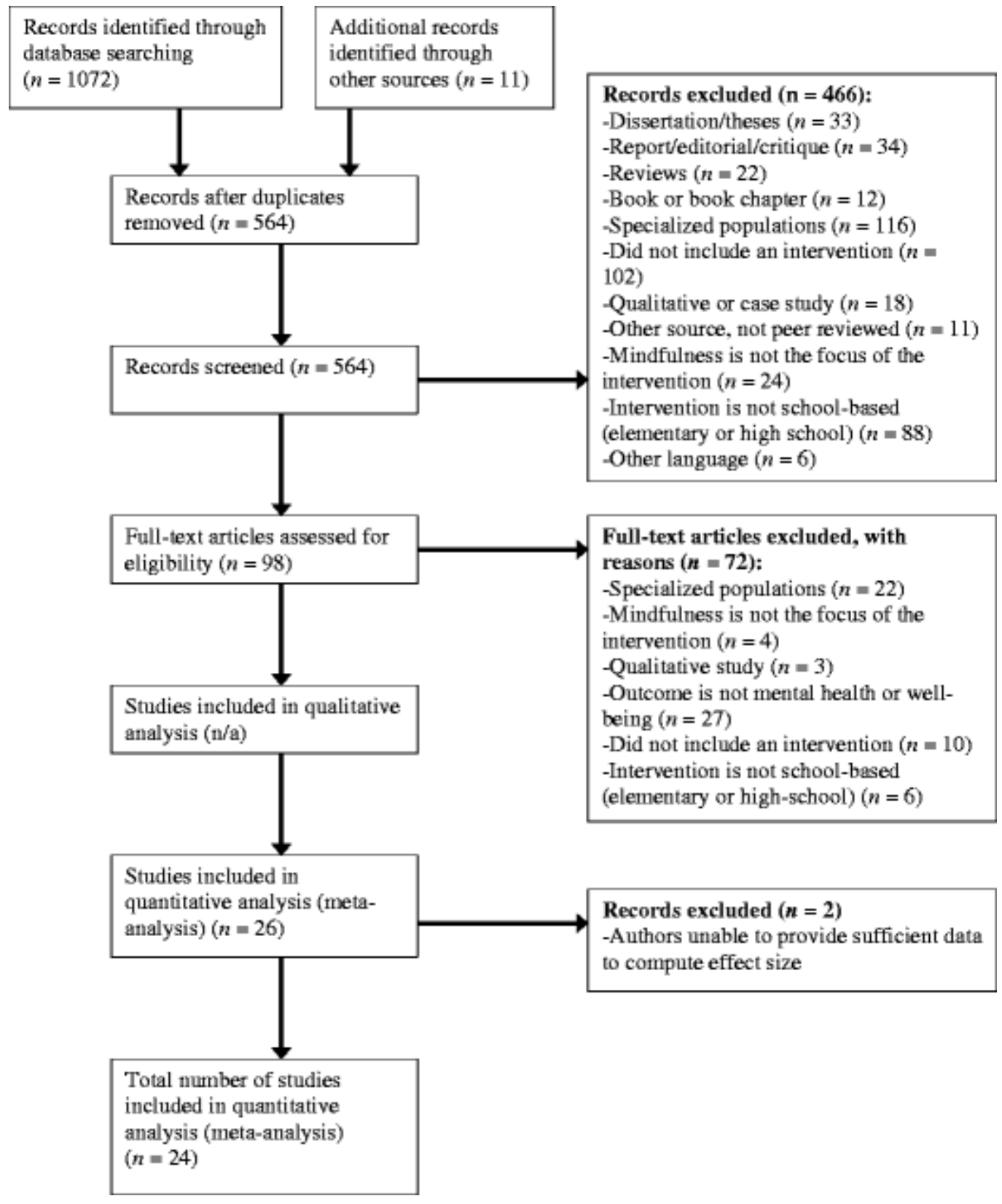


Table 1 Description and effect size analyses of the studies included in the meta-analysis

Table 1 Description and effect size analyses of the studies included in the meta-analysis

\begin{tabular}{|c|c|c|c|c|c|c|c|c|c|c|c|c|c|c|c|}
\hline Study & $\begin{array}{l}\text { Sample } \\
(N)\end{array}$ & $\begin{array}{l}\text { Age } \\
\text { (mean) }\end{array}$ & $\begin{array}{l}\% \\
\text { female }\end{array}$ & $\begin{array}{l}\text { Tx } \\
\text { group } \\
(n)\end{array}$ & $\begin{array}{l}\text { Comparison } \\
\text { group }(n)\end{array}$ & $\begin{array}{l}\text { Other } \\
\text { compari- } \\
\text { son group } \\
(n)\end{array}$ & $\begin{array}{l}\text { Type of } \\
\text { facilitator }\end{array}$ & $\begin{array}{l}\text { Tx length } \\
\text { (hours) }\end{array}$ & Relevant measures & $\begin{array}{l}\text { Pre- } \\
\text { post } \\
g\end{array}$ & $\begin{array}{l}\text { Last } \\
\text { follow- } \\
\text { up (length } \\
\text { in weeks) }\end{array}$ & $\begin{array}{l}\text { Pre- } \\
\text { follow- } \\
\text { up } g\end{array}$ & $\begin{array}{l}\text { Controlled } \\
\text { post } g\end{array}$ & $\begin{array}{l}\text { Controlled } \\
\text { follow-up } g\end{array}$ & $\begin{array}{l}\text { Quality } \\
\text { score }\end{array}$ \\
\hline $\begin{array}{l}\text { Atkinson and Wade } \\
\text { (2015) }\end{array}$ & 347 & 15.7 & 100 & $\begin{array}{l}\text { VMA } \\
\text { (138) }\end{array}$ & $\mathrm{AC}(101)$ & $\mathrm{O}(108)$ & Outside & NA & PANAS-X; CAMM & 0.26 & 24 & 0.28 & 0.16 & 0.12 & 9 \\
\hline $\begin{array}{l}\text { Bennet and Dorjee } \\
\text { (2016) }\end{array}$ & 24 & 17.7 & 42.7 & MP (11) & TAU (13) & - & Outside & 16 & $\begin{array}{l}\text { DASS-21; WHO-5; } \\
\text { BBM }\end{array}$ & 0.04 & 12 & 0.39 & -0.33 & -0.06 & 6.5 \\
\hline $\begin{array}{l}\text { Bergen-Cico et al. } \\
\quad(2015)\end{array}$ & 144 & $11.4-11.8$ & 50.5 & $\begin{array}{l}\text { MY } \\
(72)\end{array}$ & $\mathrm{AC}(72)$ & - & Teacher & 7.2 & ASRI & 0.25 & 32 & 0.22 & 0.23 & 0.44 & 6.5 \\
\hline $\begin{array}{l}\text { Bemay et al. } \\
(2016)\end{array}$ & 124 & 11.14 & 42.7 & $\begin{array}{l}\mathrm{MP} \\
\quad(124)\end{array}$ & - & - & Outside & 16 & MAAS-C; SCWBS & 0.01 & 12 & 0.03 & - & - & 5 \\
\hline Britton et al. (2014) & 100 & 11.79 & 45.54 & $\begin{array}{l}\mathrm{VMA} \\
(52)\end{array}$ & $\mathrm{AC}(48)$ & - & Teacher & 4.75 & $\begin{array}{l}\text { STAI-C (adapted); } \\
\text { CAMS-R }\end{array}$ & 0 & 12 & NA & 0.05 & - & 7.5 \\
\hline $\begin{array}{l}\text { Broderick and } \\
\text { Metz (2009) }\end{array}$ & 127 & $16.41-17.43$ & 100 & $\begin{array}{l}\text { MP } \\
\quad(104)\end{array}$ & TAU (17) & - & Outside & 6.25 & PANAS; DERS; RRS & 0.24 & - & - & 0.54 & - & 5 \\
\hline $\begin{array}{l}\text { Carsley et al. } \\
\text { (2015) }\end{array}$ & 52 & 10.92 & 53.8 & $\mathrm{O}(26)$ & $\mathrm{AC}(26)$ & - & Outside & 0.25 & STAIC-S & 0.44 & - & - & 0.07 & - & 6 \\
\hline $\begin{array}{l}\text { Crescentini et al. } \\
\text { (2016) }\end{array}$ & 31 & $7.3-7.4$ & 51.6 & MP (16) & $\mathrm{AC}(15)$ & - & Outside & 7.8 & SMFQ & 0.10 & - & - & -0.14 & - & 9 \\
\hline $\begin{array}{l}\text { Feagans Gould } \\
\text { et al. (2012) }\end{array}$ & 87 & 9.7 & 59 & $\begin{array}{l}\mathrm{MY} \\
(51)\end{array}$ & WL (46) & - & Outside & 36 & SMFQ-C; EP; RSQ & 0.40 & - & - & - & - & 3.5 \\
\hline Gouda et al. (2016) & 29 & 16.2 & 100 & MP (15) & WL (14) & - & Outside & 16 & $\begin{array}{l}\text { FMI; PSQ; HADS; TAI; } \\
\text { SES-G; SES-S; SRS; } \\
\text { ERSQ }\end{array}$ & 0.13 & 16 & 0.18 & 0.38 & - & 7 \\
\hline $\begin{array}{l}\text { Johnson et al. } \\
\text { (2016) }\end{array}$ & 308 & 13.63 & 47 & $\begin{array}{l}\text { MP } \\
\quad(111)\end{array}$ & TAU (147) & - & Outside & 6.33 & $\begin{array}{l}\text { DASS-21; WEMWBS; } \\
\text { DERS; SCS: CAMM }\end{array}$ & -0.22 & 12 & -0.14 & -0.06 & -0.21 & 9 \\
\hline Joyce et al. (2010) & 175 & 11.4 & 43.8 & $\begin{array}{l}\text { VMA } \\
(120)\end{array}$ & - & - & Teacher & 7.5 & CDI & 0.20 & - & - & - & - & 0 \\
\hline $\begin{array}{l}\text { Kukyen et al. } \\
\text { (2013) }\end{array}$ & 522 & $14.7-14.9$ & 30 & $\begin{array}{l}\text { MP } \\
\text { (244) }\end{array}$ & TAU (226) & - & Teacher & NA & $\begin{array}{l}\text { WEMWBS; PSS; } \\
\text { CES-D }\end{array}$ & 0.21 & 12 & 0.13 & 0.35 & 0.29 & 6.5 \\
\hline $\begin{array}{l}\text { Lau and Hue } \\
\text { (2011) }\end{array}$ & 48 & 15.83 & 62.5 & $\begin{array}{l}\mathrm{VMA} \\
(24)\end{array}$ & TAU (24) & - & Outside & 12 & $\begin{array}{l}\text { MAAS; FMI; SPWB; } \\
\text { DASS; PSS }\end{array}$ & 0.07 & - & - & 0.41 & - & 6 \\
\hline $\begin{array}{l}\text { Mendelson et al. } \\
\text { (2010) }\end{array}$ & 97 & $9.7-10.6$ & 60.8 & $\begin{array}{l}\mathrm{MY} \\
(51)\end{array}$ & WL (46) & - & Outside & 36 & EP; SMFQ & - & - & - & 0.13 & - & 4 \\
\hline Metz et al. (2013) & 244 & $16.4-16.5$ & 66 & $\begin{array}{l}\text { MP } \\
\quad(129)\end{array}$ & TAU (87) & - & Teacher & 5.33 & DERS; ASRES; PS & 0.52 & - & - & 0.60 & - & 5.5 \\
\hline Napoli et al. (2005) & 194 & $\begin{array}{l}6-9 \\
\text { (range) }\end{array}$ & $\mathrm{NA}$ & MP (97) & $\mathrm{AC}(97)$ & - & Teacher & 12 & TAS & - & - & - & 0.38 & - & 5 \\
\hline Raes et al. (2014) & 393 & $\begin{array}{l}14-17 \\
\text { (range) }\end{array}$ & 63.9 & $\begin{array}{l}\text { VMA } \\
\text { (167) }\end{array}$ & TAU (168) & - & Outside & NA & DASS-21 & 0.33 & 24 & 0.38 & 0.34 & 0.32 & 7.5 \\
\hline $\begin{array}{l}\text { Schonert-Reichl } \\
\text { and Lawlor } \\
\text { (2010) }\end{array}$ & 246 & 11.43 & 48 & $\begin{array}{l}\text { MP } \\
(139)\end{array}$ & WL (107) & - & Teacher & 7.5 & PANAS & -0.01 & - & - & -0.03 & - & 4 \\
\hline $\begin{array}{l}\text { Schonert-Reichl } \\
\text { et al. (2015) }\end{array}$ & 99 & 10.24 & NA & MP (48) & TAU (51) & - & Teacher & 9 & MAAS-C; SPQC & 0.38 & - & - & 0.56 & - & 7 \\
\hline $\begin{array}{l}\text { Sibinga et al. } \\
(2016)\end{array}$ & 300 & 12 & 50.7 & $\begin{array}{l}\text { MP } \\
\quad(159)\end{array}$ & $\mathrm{AC}(141)$ & - & Outside & NA & $\begin{array}{l}\text { CAMM; PSS; PANAS; } \\
\text { Brief COPE; CDI-S }\end{array}$ & - & - & - & 0.07 & - & 9.5 \\
\hline $\begin{array}{l}\text { Terjestam et al. } \\
\text { (2016) }\end{array}$ & 258 & $\begin{array}{l}10-14 \\
\quad \text { (range) }\end{array}$ & 51.68 & $\begin{array}{l}\text { MP } \\
\quad(183)\end{array}$ & TAU (124) & - & Teacher & 12 & BSPD; GSS & -0.03 & - & - & 0.03 & - & 5.5 \\
\hline $\begin{array}{l}\text { Viafora et al. } \\
\text { (2015) }\end{array}$ & 63 & $\begin{array}{l}11-13 \\
\text { (range) }\end{array}$ & 52 & $\begin{array}{l}\text { VMA } \\
\text { (28) }\end{array}$ & WL (20) & $O(15)$ & Outside & 6 & CAMM; AFQ-Y; SCS-S & 2.11 & - & - & 0.88 & - & 5.5 \\
\hline
\end{tabular}

Table 1 (continued)

\begin{tabular}{|c|c|c|c|c|c|c|c|c|c|c|c|c|c|c|c|}
\hline Study & $\begin{array}{l}\text { Sample } \\
(N)\end{array}$ & $\begin{array}{l}\text { Age } \\
\text { (mean) }\end{array}$ & $\begin{array}{l}\% \\
\text { female }\end{array}$ & $\begin{array}{l}\mathrm{Tx} \\
\text { group } \\
\text { (n) }\end{array}$ & $\begin{array}{l}\text { Comparison } \\
\text { group }(n)\end{array}$ & $\begin{array}{l}\text { Other } \\
\text { compari- } \\
\text { son group } \\
(n)\end{array}$ & $\begin{array}{l}\text { Type of } \\
\text { facilitator }\end{array}$ & $\begin{array}{l}\text { Tx length } \\
\text { (hours) }\end{array}$ & Relevant measures & $\begin{array}{l}\text { Pre- } \\
\text { post } \\
g\end{array}$ & $\begin{array}{l}\text { Last } \\
\text { follow- } \\
\text { up (length } \\
\text { in weeks) }\end{array}$ & $\begin{array}{l}\text { Pre- } \\
\text { follow- } \\
\text { up } g\end{array}$ & $\begin{array}{l}\text { Controlled } \\
\text { post } g\end{array}$ & $\begin{array}{l}\text { Controlled } \\
\text { follow-up } g\end{array}$ & $\begin{array}{l}\text { Quality } \\
\text { score }\end{array}$ \\
\hline
\end{tabular}

\begin{tabular}{llllllllllllllllll}
\hline White (2012) & 155 & 9.9 & 100 & MY & WL (85) & - & Outside & 9 & FBS; SCSI; MTAS-A & - & - & - & 0.33 & - &
\end{tabular}

$T x$ treatment group, $M P$ mindfulness program, $M Y$ mindful yoga, VMA various mindfulness activities, $O$ other, $A C$ active control, TAU treatment as usual, $W L$ waitlist control, $P A N A S-X$ Positive and Negative Affect Schedule-Expanded, CAMM Child and Adolescent Mindfulness Measure, DASS-21 Depression Anxiety Stress Scale-21, WHO-5 World Health Organization Five-Item Well-Being Index, $B B M$ body barometer measure, ASRI Adolescent Self-Regulatory Inventory, MAAS-C Mindful Attention Awareness Scale-Children, SCWBS Stirling Children's Well-being Scale, STAI-C State-Trait Anxiety Inventory-Children (Adapted), CAMS-R Cognitive and Affective Mindfulness Scale, PANAS Positive and Negative Affect Schedule, DERS Difficulties in Emotion Regulation Scale, RRS Ruminative Response Scale, STAIC-S State-Trait Anxiety Inventory for Children-State form, SMFQ Short Mood and Feelings Questionnaire, SMFQ-C Short Mood and Feelings Questionnaire-Child Version, $E P$ Emotion Profile Inventory, RSQ Responses to Stress Questionnaire, FMI Freiburg Mindfulness Inventory, PSQ Perceived Stress Questionnaire, HADS Hospital Anxiety and Depression Scale, TAI Test Anxiety Inventory, SES- $G$ General Self-Efficacy Scale, SES-S School-Related Self-Efficacy, SRS Self-Regulation Scale, ERSQ Emotion Regulation Skills Questionnaire, WEBWBS WarwickEdinburgh Mental Wellbeing Scale, SCS Self-Compassion Scale, CDI Children's Depression Inventory, PSS Perceived Stress Scale, CES-D Center for Epidemiologic Studies Depression Scale, MAAS Mindful Attention Awareness Scale, SPWB Scales of Psychological Well-being, ASRES Affective Self-Regulatory Efficacy Scale, PS Perceived Stress (Single-item). TAS Test Anxiety Scale, SPQC Seattle Personality Questionnaire for Children, CDI-S Children's Depression Inventory-short form, BSPD Psychological Distress, GSS General Stress Scale, AFQ-YAvoidance and Fusion Questionnaire, SCS-S Self-Compassion Scale for Children, FBS Feel Bad Scale, SCSI Schoolagers' Coping Strategies Inventory, MTAS-A Mindful Thinking and Action for Adolescents (Healthy Self-Regulation Subscale), $g$ Hedge's $g$ 
Table 2 Effect sizes and heterogeneity statistics for various groups of studies at different time points

\begin{tabular}{|c|c|c|c|c|c|c|c|c|c|}
\hline Study design & Time point & Division criteria & Study group & Ns & $g$ & $95 \% \mathrm{CI}$ & $p$ & $I^{2}(\%)$ & $Q$ \\
\hline \multirow[t]{14}{*}{ Within group } & \multirow[t]{9}{*}{ Post-test } & - & All & 20 & 0.23 & {$[.12, .34]$} & $<.001$ & 87.22 & 148.7 \\
\hline & & \multirow[t]{2}{*}{ Developmental period } & Middle childhood & 6 & 0.20 & {$[.03, .37]$} & $<.05$ & 74.12 & 19.32 \\
\hline & & & Late adolescence & 7 & 0.28 & {$[.17, .39]$} & $<.001$ & 59.97 & 14.99 \\
\hline & & \multirow[t]{2}{*}{ Gender } & Mixed & 17 & 0.23 & {$[.10, .37]$} & $<.001$ & 89.10 & 146.80 \\
\hline & & & Females-only & 3 & 0.24 & {$[.15, .34]$} & $<.001$ & 0.00 & 0.37 \\
\hline & & \multirow[t]{2}{*}{ Type of intervention } & Mindfulness-based yoga & 2 & 0.29 & {$[.14, .45]$} & $<.001$ & 0.00 & 0.82 \\
\hline & & & Various mindfulness activities & 6 & 0.39 & {$[.14, .63]$} & $<.01$ & 0.00 & 0.00 \\
\hline & & \multirow[t]{2}{*}{ Type of facilitator } & Teacher & 8 & 0.19 & {$[.06, .32]$} & $<.01$ & 83.43 & 42.25 \\
\hline & & & Outside & 12 & 0.28 & {$[.09, .46]$} & $<.01$ & 89.66 & 106.33 \\
\hline & \multirow[t]{5}{*}{ Follow-up } & - & All & 8 & 0.17 & {$[.04, .30]$} & $<.05$ & 87.71 & 38.28 \\
\hline & & Developmental period & Late adolescence & 4 & 0.33 & {$[.25, .42]$} & $<.001$ & 0.00 & 1.83 \\
\hline & & Type of intervention & Mindfulness-based yoga & 1 & 0.22 & {$[.04, .40]$} & $<.05$ & 0.00 & 1.83 \\
\hline & & & Various mindfulness activities & 2 & 0.34 & {$[.24, .43]$} & $<.001$ & 12.52 & 1.14 \\
\hline & & Type of facilitator & Teacher & 2 & 0.15 & {$[.06, .24]$} & $<.001$ & 0.00 & 0.73 \\
\hline \multirow[t]{16}{*}{ Between group } & \multirow[t]{12}{*}{ Post-test } & - & All & 21 & 0.24 & {$[.14, .34]$} & $<.001$ & 45.45 & 36.66 \\
\hline & & \multirow[t]{2}{*}{ Developmental period } & Middle childhood & 7 & 0.22 & {$[.04, .40]$} & $<.05$ & 38.64 & 9.78 \\
\hline & & & Late adolescence & 7 & 0.35 & {$[.18, .52]$} & $<.001$ & 32.58 & 8.90 \\
\hline & & \multirow[t]{2}{*}{ Gender } & Mixed & 17 & 0.22 & {$[.10, .34]$} & $<.001$ & 0.00 & 34.44 \\
\hline & & & Females-only & 4 & 0.27 & {$[.10, .45]$} & $<.01$ & 53.55 & 2.00 \\
\hline & & \multirow[t]{3}{*}{ Type of intervention } & Mindfulness-based yoga & 3 & 0.24 & {$[.05, .04]$} & $<.05$ & 0.00 & 0.65 \\
\hline & & & Various mindfulness activities & 5 & 0.29 & {$[.10, .48]$} & $<.01$ & 34.02 & 6.06 \\
\hline & & & Mindfulness program & 12 & 0.22 & {$[.06, .38]$} & $<.01$ & 62.26 & 29.15 \\
\hline & & \multirow[t]{2}{*}{ Type of facilitator } & Teacher & 8 & 0.28 & {$[.12, .45]$} & $<.001$ & 57.21 & 17.97 \\
\hline & & & Outside & 13 & 0.20 & {$[.07, .33]$} & $<.01$ & 33.21 & 17.97 \\
\hline & & \multirow[t]{2}{*}{ Type of facilitator and outcomes } & Teacher and mental health outcomes & 5 & 0.36 & {$[.24, .48]$} & $<.001$ & 66.91 & 24.18 \\
\hline & & & Outside and mindfulness & 7 & 0.38 & {$[.10, .67]$} & $<.01$ & 78.30 & 7.05 \\
\hline & \multirow[t]{4}{*}{ Follow-up } & Developmental period & Late adolescence & 3 & 0.22 & {$[.56, .39]$} & $<.01$ & 3.66 & 2.08 \\
\hline & & \multirow[t]{2}{*}{ Type of intervention } & Mindfulness-based yoga & 1 & 0.30 & {$[.10, .48]$} & $<.01$ & 0.00 & 0.00 \\
\hline & & & Various mindfulness activities & 2 & 0.23 & {$[.03, .43]$} & $<.05$ & 34.99 & 1.54 \\
\hline & & Type of facilitator & Teacher & 2 & 0.32 & {$[.16, .48]$} & $<.001$ & 0.00 & 0.58 \\
\hline
\end{tabular}

Ns number of studies

Fig. 2 Relation between mindfulness effect sizes and mental health and well-being effect sizes from pre- to postintervention. The studies are represented by the circles, and the size of the circle (i.e., diameter) is proportionate to the ratio of participants in the study to the total number of participants in the meta-analysis

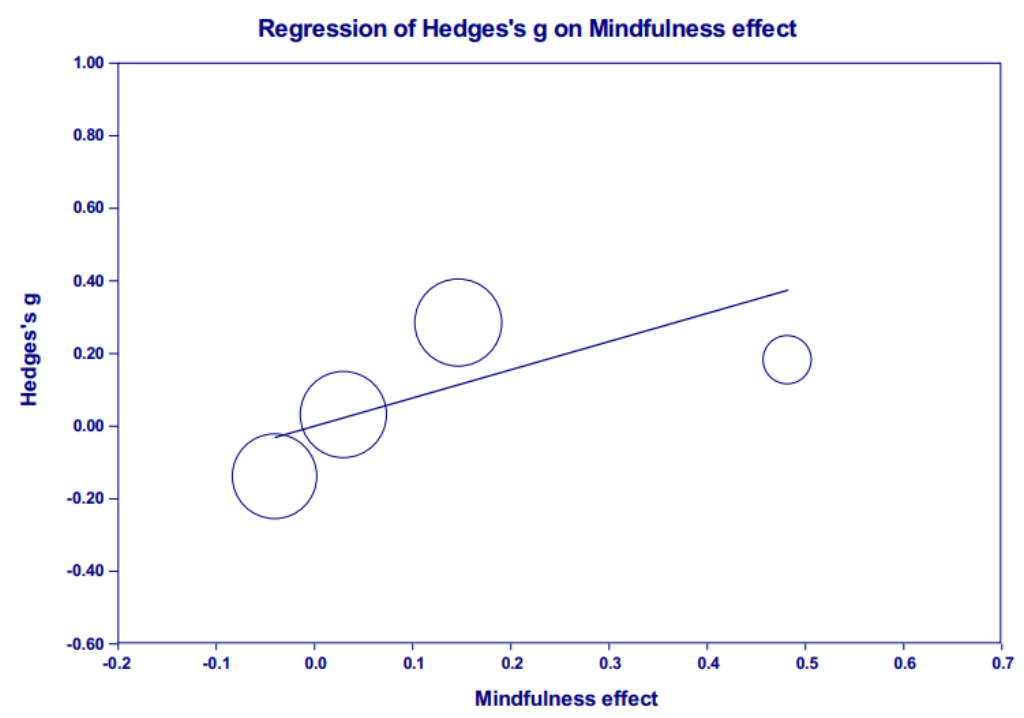


Fig. 3 Funnel plot by Hedges' $g$ of within-group studies

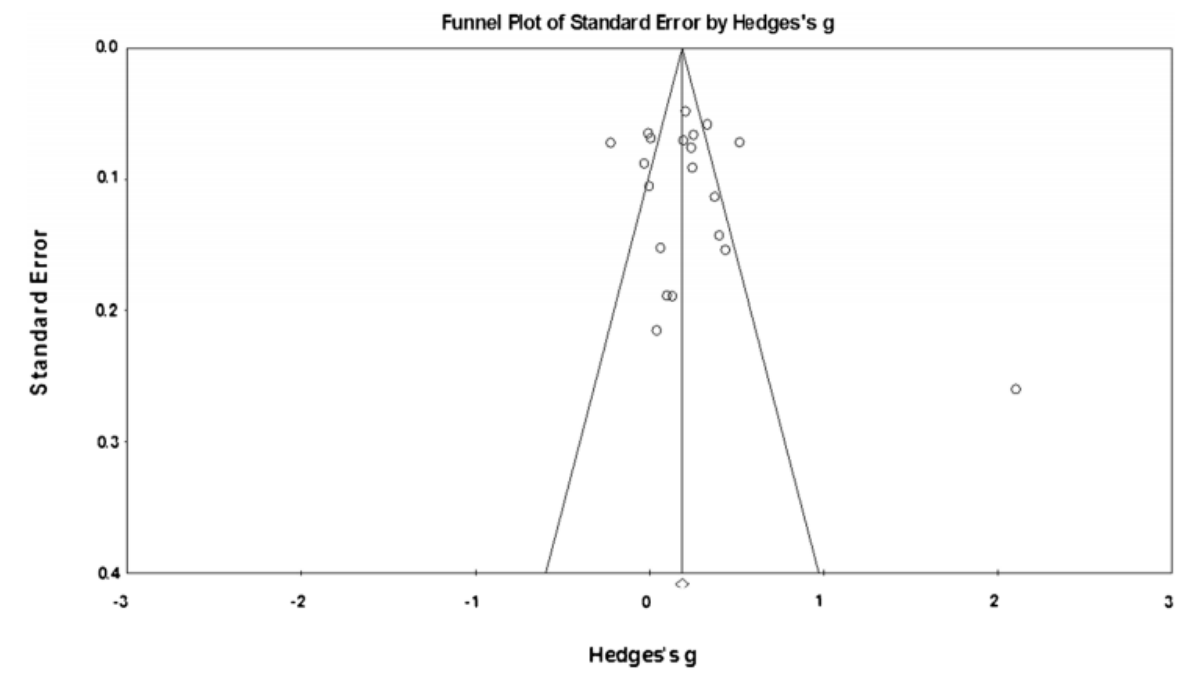

